\title{
Symptomatic hypercalcaemia precipitated by magnesium therapy
}

\author{
Amin A. Nanji* \\ Division of Clinical Chemistry, Vancouver General Hospital, 855 West 12th Avenue, and Department of Pathology, \\ University of British Columbia, Vancouver, B.C., Canada.
}

\begin{abstract}
Summary: A patient with Crohn's disease receiving vitamin $D$ and calcium had normal serum calcium levels when serum magnesium was low. Hypercalcaemia was precipitated when supplemental magnesium was given. The reason why serum calcium was initially normal is probably related to the effect of magnesium deficiency in reducing serum calcium level.
\end{abstract}

\section{Introduction}

Hypocalcaemia is a well recognized complication of hypomagnesaemia (Rude and Singer, 1981). Therefore the signs of hypocalcaemia frequently accompany magnesium depletion. Presented below is a patient with Crohn's disease who was receiving vitamin $\mathrm{D}$ and supplemental calcium in doses which would normally have resulted in hypercalcaemia. However the hypercalcaemia in this patient was prevented by the concomitant hypomagnesaemia and was precipitated when magnesium was therapeutically administered.

\section{Case report}

A 69 year old female with a ten year history of Crohn's disease and a four year history of chronic obstructive lung disease was admitted to hospital for further evaluation of pulmonary function. Four years before the present admission, the patient had a partial small bowel resection. Her daily medications included $50,000 \mathrm{IU}$ of vitamin D, $1000 \mathrm{mg}$ of elemental calcium and $3 \mathrm{~g}$ of sulphasalazine. She was not receiving any corticosteroids. Physical examination at initial admission was normal. On the eighth day after admission, serum calcium and magnesium were $2.25 \mathrm{mmol} / \mathrm{l}$ (normal 2.1-2.7) and $0.32 \mathrm{mmol} / \mathrm{l}$ (normal 0.74-1.15) respectively. She was treated with intravenous magnesium sulphate $10 \mathrm{~g}$ over $48 \mathrm{~h}$. On the 10 th day after admission, the patient had a generalized grand mal type seizure which lasted $2 \mathrm{~min}$. There were no post-

A.A. Nanji, M.B., Ch.B., F.R.C.P.

*Present address: Ottawa General Hospital, Ottawa, Ontario, Canada K1H 8L6

Accepted: 16 November 1983 ictal lateralizing neurological signs. However she was markedly confused. Laboratory tests showed serum calcium $3.9 \mathrm{mmol} / 1$, magnesium $1.0 \mathrm{mmol} / \mathrm{l}$ and serum albumin $35 \mathrm{~g} / \mathrm{l}$. Serum sodium, potassium, chloride, bicarbonate, urea nitrogen, creatinine, and arterial blood $\mathrm{pH}$ and gases were normal. The patient was treated with intravenous saline and frusemide. This resulted in a decrease in serum calcium accompanied by a marked improvement in the patient's mental status. The patient did not have any more seizures. The dose of vitamin D and calcium were both reduced and no further magnesium supplements were given.

\section{Discussion}

The above patient demonstrates an unusual manifestation of magnesium deficiency; namely that of 'masking' hypercalcaemia. The dosage of vitamin $\mathbf{D}$ and calcium that the patient received will in some patients cause hypercalcaemia (Habener \& Potts, 1979). Occurrence of hypercalcaemia in this patient was probably initially prevented by the presence of hypomagnesaemia; replacement of magnesium precipitated hypercalcaemia. Other causes that could have contributed to acute hypercalcaemia such as volume depletion, thiazide diuretics and immobilization were not present.

There are several factors responsible for lowering serum calcium in magnesium deficiency. These include failure of parathyroid hormone production and release, hypercalciuria, altered equilibrium for calcium between bone and extracellular fluid and altered vitamin D metabolism (Rude \& Singer, 1981; Massry, 1979). 
The occurrence of a seizure disorder secondary to hypercalcaemia is rare (Hines \& Suker, 1973). The mechanism by which hypercalcaemia causes seizures is poorly understood. It has been proposed that excess calcium in the presence of decreased magnesium concentration increases transmitter release at presyn-

\section{References}

CRYER, P.E. \& KISSANE, J.M. (1979). Malignant hypercalcemia, American Journal of Medicine, 67, 486.

HABENER, J.F. \& POTTS, J.F. (1979). Clinical features of primary hyperparathyroidism In Endocrinology L. DeGroot, (ed.) p. 708. Grune and Stratton: New York.

HINES, J.R. \& SUKER, J.R. (1973). Some unusual manifestations of parathyroid disease. Surgical Clinics of North America, 53, 221. aptic nerve endings and causes seizures (Cryer and Kissane, 1979).

In summary, the above patient demonstrates that in certain patients who are receiving vitamin $\mathbf{D}$ and calcium, magnesium supplementation may precipitate hypercalcaemia.

MASSRY, S.G. (1979). Disorders of magnesium metabolism. In Strauss and Welt's Diseases of the Kidney L.E. Earley and C.W. Gottschalk, (eds.) p. 1639. Little Brown and Company: Boston, USA.

RUDE, R.K. \& SINGER, F.R. (1981). Magnesium deficiency and excess. Annual Review of Medicine, 32, 245. 